\title{
Teaching Research on Conjunction of English and Mother Language
}

\author{
Shirong Cui
}

International School, Zibo Vocational Institute, Zibo, 255314, China

\author{
Keywords: English, Mother language, Conjunction
}

\begin{abstract}
In recent years, China's has already obtained rapid economic and cultural development. As a result, foreign exchange is also increased accordingly. As a universal language in the world, English has received more and more attention from social and educational circles. However, such attention leads to the issue of westernization of the present English teaching, thus leading to deficiency of Chinese culture in English teaching. Moreover, serious imbalance of Chinese and English will result in students' deviation in understanding and translation in the learning process of English. Therefore, integration of English and mother language is of the most importance for the present English teaching in China.
\end{abstract}

\section{Introduction}

After China's access to WTO, foreign commercial exchange increases continuously. Economic development also more trends to globalization. Therefore, the society naturally has higher requirements for professional literacy and integrative competence of English professionals. More and more people pay attention to learning and teaching of English. At present, China's English teaching extremely pursues for localization. As a result, western cultural knowledge is extremely emphasized, leading to serious deficiency of Chinese culture in English teaching. However, Chinese language culture is overlooked, having great influence on students' comprehension and translation of English in the learning process. In practical teaching process, therefore, we should properly integrate knowledge of mother language into English teaching, so as to further give play to the role of mother language in promoting English teaching and improving students’ English learning efficiency.

\section{Present Situation of Integration of Mother Language and English Teaching \\ Great limitation of thinking and insufficient understanding of the function of mother language}

At present, most Chinese students devote themselves to improving their English level. In the practical process of communication with foreigners, however, it is very difficult to communicate in English and convey Chinese culture. It is even more difficult for us to write in English a paper about Chinese culture. Such circumstance is mainly resulted from most students' failure to have a definite cognition of nature and purpose of language learning process. In other words, they have no sufficient understanding of language input process and output process. In addition, students, under the influence from traditional teaching concept, use single learning mode for English learning. They mainly depend on mechanical memory. Moreover, they paid much attention to learning of the target language and failed to realize the important role of their mother language in learning of their mother language. Therefore, they are unable to use the mother language to correctly unscramble the knowledge about the target language ${ }^{[1]}$.

\section{Deviation in teaching philosophy has an impact on teaching orientation.}

In the present English textbooks, lots of foreign references and materials are used to enhance students' knowledge understanding. However, these references are completely irrelevant to Chinese culture. Most students and teachers fail to realize that the purpose of our English learning is to promote internationalization of China's economic and cultural development, enhance exchange between China and other countries, allow Chinese culture to step out of China, and thus improve China's competition in the international market instead of transforming English into our mother 
language. As a result, excessively westernized teaching, loss of native culture and other similar phenomena are caused, making English teaching deviate its original purpose. At the same time, students have misunderstandings of their goals of English learning. Naturally, teaching efficiency cannot be guaranteed.

\section{Insufficient understanding of native culture leads to shortage of interest in Chinese culture conveying.}

Undoubtedly, introduction of British, American and European plays and films is quite helpful for college students' English learning. Appreciation of British and American plays and films can further improve students' oral English expression abilities, enrich their English vocabulary, and broaden their English expression channels. At the same time, however, these elements impact the cultural cognition system of these students. In European and American plays and films, excessive beautification of European and American culture even makes students to have unreal yearnings for European and American countries and thus to have the psychology of blindly fawning on foreigners. More seriously, they even look down on the culture of their own country. Such situation is quite unfavorable for students' future development and social development. Moreover, it also goes against the purpose of English teaching of "convey national culture, promote international exchange” [2].

\section{Approaches Used to Promote Effective Integration of English and Mother Language}

To understand the importance of mother language in English teaching, we also need to find out measures and methods for effective integration of the two items. As long as we have effective measures and correct orientation, we can further integrate mother language with English teaching.

\section{Improve textbook contents}

At present, the contents of most English textbooks and references are completely irrelevant to Chinese culture in China. Few parts of Chinese language and culture are available. In other words, viewed from the contents of English textbooks, the feature of less attention to English and Chinese integration has already been obviously reflected. To radically change this situation, we should start from the contents of textbooks. Schools should make further improvement to chinization of their textbooks, and penetrate Chinese culture into more English textbooks. Certainly, relevant governmental education departments should also provide great supports, make further improvement to national popular textbooks, and integrate more Chinese elements, so as to let the philosophy of English \& Chinese integration comprehensively penetrate into the field of English teaching in various regions. Under the circumstance of no change in the contents of textbooks, teachers can give play to their creativity and guidance ability according to the contents of present textbooks, and skillfully integrate more elements of our mother language into English ${ }^{[3]}$. While explaining sentence pattern, teachers can make a comparison between Chinese expression pattern and English expression pattern, letting students consolidate their Chinese expression modes while understanding English sentence patterns. In English sentence pattern, for instance, sentences used to state time and site are usually put at the end. This sentence pattern is completely different from Chinese expression. British people usually say "I will have a meeting at ten o clock". However, it is different in Chinese. Therefore, Chinese foundation is of great important, if we want our students to have a better understanding of English knowledge.

\section{Improve teacher's ability and teaching thought}

Teachers are important guiders of students in the entire learning process. A teacher's thought and ability decide students' learning orientation and final outcome. Therefore, only teachers can really emphasize integration of English and Chinese, take inheritance of Chinese culture internationalization as the teaching goal, really improve students' consciousness of Chinese culture, and let students pay more attention to inheritance of their national culture. To effectively integrate Chinese culture into English teaching, therefore, teachers should first change their thoughts, make continuous perfection to their knowledge system, fully realize the purpose of English learning (for better advocacy of Chinese culture in future international exchange), and embody their excellent quality as Huaxia people. Then, teachers should penetrate such teaching thoughts into their teaching 
details, let their students take this as their learning orientation, emphasize improvement to their knowledge about Chinese culture, and allow students to feel a more profound atmosphere of national culture in English classroom ${ }^{[4]}$. If teachers have the awareness of national culture exchange and cultural inheritance, students will also be edified by their teachers, take cultural inheritance as their learning goals, and become messengers of conveying Chinese culture and promoting international affiliation.

\section{Change teaching mode}

A teacher's teaching mode decides his/ her ultimate teaching outcome. It is also the same in English teaching process. Only when teachers are willing to improve their teaching mode and use more diversified teaching modes that students like to integrate our mother language culture into English teaching, they can practically improve their students' English \& Chinese application abilities, and cultivate their thinking of cultural inheritance and cultural exchange. For instance, teachers can adopt the mode of drama translation performance to enhance students' cultural integration, or divide the students into different groups, and ask each group of students to translate and perform a segment of Thunderstorm. Such pattern can enhance students' understandings of Chinese cultural works, and further intensify their English comprehension and translation abilities. For cultures transmitted from China to foreign countries in the early stage, teachers can adopt the mode of storytelling or video display to enhance students' understandings. For instance, when talking about relevant contents of food, teachers can prepare some videos for a comparison between Chinese food and foreign food, and use in combination the videos to explain some stories about introduction of Chinese food to foreign countries. Initially, ice cream was produced in the late Tang Dynasty. Till the $13^{\text {rd }}$ century, it was brought to Italy by traveler Marco Polo. Since then, ice cream appeared in foreign countries. Dumpling was also invited by Zhang Zhongjing, a medical sage in the Eastern Han Dynasty. Then, it was introduced to foreign countries. We have many varieties such as Italian dumplings. All these are products of integration of western culture and Chinese culture. Teachers should utilize their innovation thinking and cultural integration thinking to make better interactions, so as to make further improvement to students’ English learning efficiency and cultural inheritance awareness ${ }^{[5]}$.

\section{Optimize course design}

For students, Chinese culture has a long history. Compared with innovative European and American culture with a short development course, Chinese culture gives a sense of solemnity to Chinese students. Therefore, teachers should make further optimization to course design, allow students to feel mutual coordination and integration between Chinese language culture and European and American language culture as well as innovation of Chinese language culture, so as to make students to integrate English and Chinese culture together in a better way and study in a synergetic and complementary way. To enhance comparison between Chinese and foreign culture, teachers should properly add diversified links (such as "find the difference") into course design scheme. For instance, when talking about relevant contents of building, teachers can display at the same time pictures about Chinese and foreign buildings, letting students state their differences in English after group discussion. When talking about "celebration”, teachers can discuss according to the most important festivals in Britain \& America and China, and talk about the most important festivals and celebrations in both countries. Such contrastive and integrative course design can further intensify students' understandings of Chinese and foreign culture, find features of their national culture in the learning and understanding process, and learn how to express various cultural customs of their country in English.

\section{Emphasize the second classroom}

Extracurricular second classroom activity is the most effective channel used to mobilize students' learning interest. In this aspect, teachers can organize students to establish drama clubs, cover singing clubs and other interesting organizations, and promote integration of Chinese and English culture by virtue of bilingual drama performance, Chinese-English song cover singing, reading and other activities. In the organization and performance process of bilingual drama performance, students translate, remember and display words. All these scenes can effectively improve their English application and comprehension abilities. It is also the same for cover version singing. The translation 
and practice process can intensify their compression and application of both languages. However, reading and similar activities can effectively improve their reading volume. Besides, teachers can also organize students to read $\mathrm{Xi}$, Lukashenko pledge to boost relations, Chinese stock market frenzy leaves investors cautious and other papers about national situation in CHINADAILY, discuss with students about their opinions, and allow students to express their opinions. Thus, students are trained in expression competence. At the same time, teachers can have deepened understandings of the connotation of our national culture. Additionally, teachers can also allow students to organize some extra-curricular activities helpful for benign competition, such as bilingual recital contest and debate competition, letting students intensify their cultural knowledge in the competition process and further enrich their extra-curricular life. This is a win-win program.

\section{Conclusion}

To sum up, China's commercial exchange and cooperation with other English countries have also continuously increased with continuous tendency of internationalization. Therefore, the society puts forward more and higher requirements for quality and professional skills of English-related talents. In the process of international culture exchange, English is a communication tool. At the same time, it also shoulders the important task of conveying national culture. Thus, it is necessary for English teachers to make deep exploration and reflection against integration of Chinese and English, give full play to the important role of mother language in English learning, let two cultures integrate with each other in a more coordinated and more natural way, create a better English - Chinese integration learning environment to students, allow students to feel more Chinese culture in the English learning process, and make students have deeper understandings of relevant knowledge about English and Chinese.

\section{References}

[1] Xie Gang and Li Nan, Discussion on Conjunction of English Teaching and Mother Language, Academic Exploration, 2013 (5): 103-105;

[2] Deng Yuanfang, Discussion on Conjunction of English Teaching and Mother Language, English on Campus, 2014 (9): 6-6;

[3] Niu Wenqian, Discussion about Conjunction of English Teaching and Mother Language, English on Campus, 2015 (3): 110-110;

[4] Wu Shengxian, Discussion on Function of Mother Language in English Teaching, Heihe Education, 2013 (11): 30-30;

[5] Liu Junying, Analysis on Influence of Mother Tongue Transfer on English Learning, Teaching \& Administration, 2013 (4): 97-99. 